\title{
Regulatory Policies for Demand-Driven Innovation by Heterogeneous Firms
}

\author{
Mei Lin \\ The University of Hong Kong \\ linm@hku.hk \\ Shaojin Li \\ Renmin University of China \\ shaojinl@gmail.com
}

\author{
Andrew B. Whinston \\ The University of Texas at Austin \\ abw@uts.cc.utexas.edu
}

\begin{abstract}
We investigate the innovation rate under the impact of business cycles to understand R\&D activities and to derive implications for public policies. Combining price competition and endogenous market structure with the framework of dynamic game, we study the Markov perfect equilibrium where heterogeneous firms choose whether to participate in the innovation race and the innovation rate. Based on the analytical results derived from the price competition, we find that increased income per capita tends to improve aggregate innovation, while incumbents reduce their innovation efforts as more entrants enter the innovation race, the competition pressure increases. Income inequality shocks may reduce or have no impact on innovation, depending on equilibrium region. We find subsidies to reduce innovation incentive, and policies such as tax incentives that reduce the variable $R \& D$ costs to have consistently positive effects. Our findings on both the income shocks and policies are consistent with the empirical evidences.
\end{abstract}

\section{Introduction}

In an economic downturn, the distortion in the consumer demand caused by the income shifts discourages the expansion and renewal of the supply chain operations. As many firms struggle to adjust their business processes and cut costs to adapt to the shrunken market demand, survival becomes the imminent concern, which may dissolve the incentives to continually reinventing more agile infrastructures for long-term success. This adverse effect propagates throughout the industry and results in an economy-wide stagnation and reduction of firms' investment in innovation.

These issues of a recession heighten the awareness for innovation. The lack of integration among the entities along the supply chains calls for higher level regulatory initiatives. In responding to the current economic meltdown, the Obama administration has allocated large sums of funding for the development of science and engineering to stimulate innovation efforts [10]. $\$ 22.5$ billion dollars are distributed among the major research agencies including the National Science Foundation (NSF), the National Institutes of Health (NIH), the Department of Energy (DOE), the National Institute of Standards and Technology (NIST), etc. [14]. In the meantime, the Obama administration is attempting to make the $\mathrm{R} \& \mathrm{D}$ tax credit permanent to increase the incentive for innovation by businesses [21]. The similar phenomena are observed around the globe - governments of China, United Kingdom, Russia, Australia, etc. are also providing generous amounts of funding support for the R\&D sectors [15] [20].

In order to evaluate the impact of these research stimuli, it is critical to understand the implications of different innovation policies. In this paper, using a dynamic game framework we analyze innovators' equilibrium decisions and R\&D efforts facing economic shocks, and explore the impact of public policies on R\&D through reducing innovators' sunk costs and variable costs. Our findings provide theoretical explanations for firms' $R \& D$ activities through business cycles, when firms make their decisions facing future uncertainties. We also show strong theoretical support for the empirical evidence on innovation policies in the forms of government subsidies and tax incentives.

By emphasizing the demand-driven innovations, our model characterizes one of the key elements, consumer demand, that is driving the value chains. Specifically, we answer the questions of how different income shifts (income inequality and income per capita) impact the innovation efforts. Moreover, the innovator heterogeneity allows us to derive insights on why some firms, such as Apple, Google, Dell, 
etc., successfully continue the initiatives in innovating their information services and reinventing their business models, while others come to a halt in a fragile economy. For example, Apple retained its enormous sales growth, Dell produced flows of new designs and products, and Google further pushed its Cloud-based online software suites, which are essential for the digital supply chains.

On innovation activities within fluctuating business cycles, one argument states that under unfavorable economic climates firms cut back on R\&D in order to focus on their core business and that motivating continued innovation efforts is crucial for reviving the economy [16]; However, others argue that it is exactly the recession that provides the strongest driving force for firms to explore drastically new ideas for a chance to survive and thrive. In the research front, empirical studies has shown strong support for the procyclicality of R\&D activities [3], while other recent work demonstrates that recession should foster innovation [2] [5].

Barlevy examined the inefficient procyclical allocation of innovation within business cycles, and analyzed the problem based on the externality of R\&D that benefits firms aside from the innovator [3]; Taking a different angle, we look at the heterogeneity in innovators' variable costs. As Schumpeter stated, "[profit] is the premium which capitalism attaches to innovation" [17], entrepreneurs enters the R\&D race based on their evaluation of future market profitability with the potential costs, which are conditional on their capital, resources, and capability. We model the impact of business cycles as exogenous income shocks that shift the market demand; In a recession, consumers have lower disposal income and have less desire to purchase the higher quality products. Our results show that more efficient (low variable $R \& D$ cost) firms innovate more in a recession due to dampened competition as less efficient (high variable $R \& D$ cost) firms perceive lower future profits and exit the innovation race. When less efficient firms innovate in the boom, the efficient firms innovate at a lower intensity in equilibrium, because intensified competition reduces innovation. However, in the latter case the aggregate innovation rate is higher since both types of firms are innovating, which is consistent with the empirical evidence in the literature and reconciles the conflicting view points on innovation activities in a downturn.

Based on the analytical results, we demonstrated several numerical examples and derived insights for innovation policies. By varying the $R \& D$ fixed cost, we found that subsidies that directly lower this cost may not stimulate innovation, be- cause it reduces innovating firms' incentive to offset the sunk cost while maximizing profits; in other words, firms become "lazier." However, at a very large fixed cost, the industry only has efficient firms innovating, where the aggregate innovation rate is lower than in an industry where all firms choose to innovate. The empirical literature on subsidy policies also shows this inconsistency [9]. On the other hand, we find that reducing variable $R \& D$ cost has a generally favorable effect and encourages both types of firms to innovate at a higher rate. Various R\&D tax incentives, such as tax credits, are examples of policies that directly affect the $R \& D$ variable cost. Our finding is supported by wide empirical evidence on positive impact of tax incentives on firms' innovation efforts [7] [11] [4].

This work also offers theoretical contributions to the related literature. Foellmi and Zweimuller studied the effect of income inequality on growth using non-homothetic consumer preference [8]. In their formulation, both the poor and rich consumer segments either all purchase one good or not. Our model incorporates the consumer tastes as well as income levels, under which market segmentation occurs for each income level.

We also account for the heterogeneity of competing innovators at different costs; As a result, we are able to contrast different types of firms as innovation rate either changes smoothly or jumps with income, and infer policy implications. Furthermore, the explicit characterization of vertical differentiation shows that the equilibrium can fall under several cases. The findings under these cases imply that the segmentation of consumers at various income levels leads to different results when examining how income parameters affect innovation rate, and are in sharp contrast with the findings in [8].

Studies in the industrial organization literature have examined firm-level R\&D issues. However, this line of work has mostly focused on a static model that limits the analysis to a single or finite period model [12] [13], with a few exceptions such as Segal and Whinston's work on anti-trust policy and innovation [18]. We adopt their framework with an extension to include dynamic draws of innovators' types in terms of their variable costs. Moreover, we endogenize entrant's and incumbents' profits using a consumer income distribution and product quality levels to include the demand factor, which is absent from Segal and Whinston's work. The shifting of business cycles that is reflected in consumer income change plays a major role in incentizing potential entrants' R\&D efforts, as consumers' demands directly determines the future rewards of the innova- 
tors.

Based on Shaked and Sutton, the seminal work on market equilibrium with vertical differentiation [19], we relax the assumption of uniform income distribution by generalizing the distribution, and further refine their model with a taste shock for consumers at all income levels. The taste shock reflects the heterogeneity of consumers' preferences toward newer technologies. This setup also lifts the distribution restriction imposed in most analytical work, in turn permits matching of actual data moments to find results relevant to realistic economic settings.

The rest of the paper is organized as follows. We describe the price competition game and analyze the endogenous market structure in Section 2 . Then we present the innovation race and analyze the firm's innovation decisions in Section 3. Section 4 discusses the reaction of equilibrium innovation rate to different income shocks and regulatory policies. Section 5 concludes.

\section{Price Competition and Market Structure}

The present paper develops a dynamic model with price competition on differentiated products in each period. This model connects consumers' demand and firms' innovation effort through endogenous market structure. The analysis shows the impact of the aggregate economic conditions from the demand side on aggregate innovation. In this section, we describe the model setup for the static price competition, and analyze firm's pricing strategies and market segmentation based on consumers' preferences. In Section 3, we will analyze the firm's innovation behaviors.

Our framework has an infinite horizon, where each discrete period has the discount factor $\beta \in$ $(0,1)$. In each period, there exists two groups of firms differing in their objectives and actions. The incumbent firms compete in price in the product market, into which the innovations are introduced as the latest generation, or highest quality, good; The potential entrants are the firms making innovation decisions in the $R \& D$ race. This section formulates the competition and market structure in the product market among the incumbents. The innovators, prior to successfully innovating and entering the product market, choose whether to enter the $R \& D$ race and, if so, the equilibrium level of innovation effort. That is presented in Section 3.

Using the dynamic programming approach, we solve for the stationary Markov perfect equilibria of the infinite-horizon game. This section analyzes the existence and uniqueness of Nash equilibrium of the pricing competition game in a static vertical differentiation model. Assuming firms do not collude, the pricing strategies in the analysis here is part of the stationary Markov perfect equilibrium of the dynamic game.

\subsection{Consumers}

The setup here extends Shaked and Sutton [19] by generalizing the consumer income distribution. A continuum of consumers are heterogeneous in their income levels and tastes for the product. Denote a consumer's income by $I \in\left\{I_{H}, I_{L}\right\}$, such that $I_{L}<I_{H}$, and $\triangle=I_{H}-I_{L}$; let $\pi_{L} \in[0,1]$ and $\pi_{H} \in[0,1]$ be the proportion of low and high income segments respectively. $\pi_{H}+\pi_{L}=1$. Define income per capita $\bar{I}=I_{H} \pi_{H}+I_{l} \pi_{L}$, the relative high income ratio $q_{h}=\frac{I_{H}}{\bar{I}}$. Thus the triple $\left(\bar{I}, q_{h}, \pi_{H}\right)$ characterizes the income distribution of the economy. Furthermore, each consumer experiences a taste shock denoted by the random variable $z$ that follows the uniform distribution: $z \sim U[\underline{z}, \bar{z}]$. For simplicity, a consumer's taste is fixed across her life.

In each period, consumers observe firms which produce vertically differentiated, substitute goods as a result of the innovation race, described in section 3.. Denote $k=1, \ldots, n$ as an index of the quality of products, where a higher $k$ represents a higher quality.

The consumers are utility maximizing:

$$
\max U(I, z, k)=u_{k} *(I+z)
$$

where $u_{k}=e^{a k}$ following [6] and $u_{0}<u_{1}<\ldots<u_{n}$. Each consumer's utility is defined by the utility for consuming a certain quality good weighted by the consumer's disposable income and taste. Let $C_{k}$ be the relative utility difference between products $k$ and $k-1$, and $C_{k}>1$ :

$$
C_{k}=\frac{u_{k}}{u_{k}-u_{k-1}}=\frac{e^{a}}{e^{a}-1}=C
$$

Define $z_{k}^{j}$ as the indifference taste level in the income segment $j$, so that the consumer with taste $z_{k}^{j}$ is indifferent between product $k$ and $k-1$ at their respective prices. So for $j \in\{L, H\}$,

$$
U\left(I_{j}-p_{k}, z_{k}^{j}, k\right)=U\left(I_{j}-p_{k-1}, z_{k}^{j}, k-1\right)
$$


From here, we derive

$$
\begin{aligned}
z_{1}^{j} & =p_{1} C_{1}-I_{j} \\
z_{k}^{j} & =p_{k-1}\left(1-C_{k}\right)+p_{k} C_{k}-I_{j}
\end{aligned}
$$

Then consumers within each income segment with taste $z>z_{k}^{j}$ has the preference order $\left(k, p_{k}\right) \succ$ $\left(k-1, p_{k-1}\right)$.

Proposition 1. The indifference taste levels $z_{k}^{j}$ have the following properties:

$$
\begin{aligned}
& \text { 1. } \forall k, z_{k}^{j}>z_{k-1}^{j} \text {, for } j \in\{L, H\} \text {; } \\
& \text { 2. } \forall k, z_{k}^{H}<z_{k}^{L} \text {; } \\
& \text { 3. } \forall k, z_{k}^{H}+I_{H}=z_{k}^{L}+I_{L} \text {, so } z_{k}^{H}+\triangle=z_{k}^{L} \text {. }
\end{aligned}
$$

Proposition 1 outlines the mathematical properties, which are used for the proofs and analysis of the later analytical findings.

\subsection{Market Structure Analysis}

Firms' revenue functions take different forms depending on market segmentation, which is determined by the values of the exogenous parameters (e.g., those for income distribution and taste) and by the equilibrium prices. For example, a firm's revenue function will not include the term describing the low-income segment, if in equilibrium its price does not capture any low-income consumers; and the levels of high and low incomes as well as upper and lower bounds for consumers' taste impact such segmentation in equilibrium. The revenue functions for $n$ firms below are listed by these cases.

For $k=1, R_{1}\left(p_{1}, p_{2}, \ldots, p_{n}\right)$, the revenue of firm 1 given the price of his product $p_{1}$, is expressed in terms of the following cases:

$$
\begin{cases}p_{1}\left(z_{2}^{L}-\underline{z}\right) \pi_{L}, & z_{2}^{H} \leq \underline{z} \text { and } z_{2}^{L} \geq \underline{z} ; \\ p_{1}\left(z_{2}^{H}-\underline{z}\right) \pi_{H}+p_{1}\left(z_{2}^{L}-\underline{z}\right) \pi_{L}, & z_{1}^{L} \leq \underline{z} \text { and } z_{2}^{H} \geq \underline{z} ; \\ p_{1}\left(z_{2}^{H}-\underline{z}\right) \pi_{H}+p_{1}\left(z_{2}^{L}-z_{1}^{L}\right) \pi_{L}, & z_{1}^{H} \leq \underline{z} \text { and } z_{1}^{L} \geq \underline{z} ; \\ p_{1}\left(z_{2}^{H}-z_{1}^{H}\right) \pi_{H}+p_{1}\left(z_{2}^{L}-z_{1}^{L}\right) \pi_{L}, & z_{1}^{H} \geq \underline{z} .\end{cases}
$$

In the first two cases, the lowest taste consumers among the low-income segment strictly prefer purchasing the low-quality product than not buying the low-income market is covered; In case 1, all highincome consumers will purchase the high-quality product, whereas in case 2, they are split between two products. In the last two cases, some low-taste consumers in the low-income segment would not purchase even the low-quality product - the lowincome market is not covered; In case 3, the highincome segment is covered, whereas in case 4 , the high-income market may not be covered.

For $1<k<n, R_{k}\left(p_{1}, p_{2}, \ldots, p_{n}\right)$, the revenue of firm $k$ given the price of his product $p_{k}$, is,

$$
\begin{cases}p_{k}\left(z_{k+1}^{H}-\underline{z}\right) \pi_{H}+p_{k}\left(z_{k+1}^{L}-z_{k}^{L}\right) \pi_{L}, & z_{k}^{H} \leq \underline{z} \\ p_{k}\left(z_{k+1}^{H}-z_{k}^{H}\right) \pi_{H}+p_{k}\left(z_{k+1}^{L}-z_{k}^{L}\right) \pi_{L}, & z_{k}^{H} \geq \underline{z}\end{cases}
$$

And for $k=n$,

$$
R_{n}\left(p_{1}, p_{2}, \ldots, p_{n}\right)=p_{n}\left(\bar{z}-z_{n}^{H}\right) \pi_{H}+p_{n}\left(\bar{z}-z_{n}^{L}\right) \pi_{L} .
$$

Based on the first-order conditions, we can derive the following lemma.

Lemma 1. Let $\bar{z}<\min \left\{2^{N} \underline{z}+\left(2^{N}-1\right) I_{L}-\right.$ $\pi_{H} \Delta,\left(2^{N-1} \pi_{L}+2\right) \underline{z}+\left(2^{N-1} \pi_{L}+2^{N-1}-1\right) I_{L}+$ $\left.\pi_{H} \Delta\right\}$, for any Nash equilibrium in this vertically differentiated market, at most $N$ firms (producing products of qualities $n, n-1, . . n-(N-1)$ ) obtain positive market shares.

We have derived the necessary condition for an $\mathrm{N}$-firm equilibrium in Lemma 1. To further analyze the existence of such equilibrium, for tractability we apply the lemma to the $\mathrm{N}=2$ case and consider a two-firm market.

Proposition 2. Let $\bar{z}<\min \left\{4 \underline{z}+3 I_{L}-\right.$ $\left.\pi_{H} \Delta,\left(2 \pi_{L}+2\right) \underline{z}+\left(2 \pi_{L}+1\right) I_{L}+\pi_{H} \Delta\right\}$, for any Nash equilibrium in this vertically differentiated market, at most two firms (producing products of qualities $n$ and $n-1)$ obtain positive market shares.

\subsection{Two-firm equilibrium}

$$
\begin{aligned}
\text { Define } V & =\frac{u_{2}-u_{0}}{u_{2}-u_{1}}=\frac{C_{2}-1}{C_{1}}+1, \text { thus we have } \\
p_{1} & =\frac{z_{1}^{j}+I_{j}}{C_{1}} \\
p_{2} & =\frac{z_{2}^{j}+I_{j}+\left(z_{1}^{j}+I_{j}\right)(V-1)}{C_{2}}
\end{aligned}
$$

Referring back to Equations (3), we get the following FOCs for firm 1, listed in the order of the corresponding cases: 


$$
z_{2}^{L}=\left\{\begin{array}{l}
\underline{z}+\left(z_{1}^{L}+I_{L}\right)(V-1) \\
\pi_{H} \Delta+\underline{z}+\left(z_{1}^{L}+I_{L}\right)(V-1) \\
\pi_{H}(\Delta+\underline{z})+z_{1}^{L} \pi_{L}+\left(z_{1}^{L}+I_{L}\right)\left(V-1+\pi_{L}\right) \\
z_{1}^{L}+\left(z_{1}^{L}+I_{L}\right) V ;
\end{array}\right.
$$

Firm 2's FOC is either of the following ordered as the profit functions:

$$
z_{2}^{L}=\left\{\begin{array}{l}
\frac{1}{2}\left[\bar{z}-I_{L}-\left(z_{1}^{L}+I_{L}\right)(V-1)+(\bar{z}-\underline{z}) \frac{\pi_{H}}{\pi_{L}}\right] \\
\frac{1}{2}\left[\bar{z}+\pi_{H} \Delta-I_{L}-\left(z_{1}^{j}+I_{j}\right)(V-1)\right]
\end{array}\right.
$$

Figure 1 plots firm 1's FOCs for different ranges of $z_{1}^{L}$. Regions 1 through 4 in the figure correspond to the four cases of Equation (3); and Regions 5, 6 and 7 are the regions between the adjacent cases. In these regions, in equilibrium one firm varies its price while the other holds its price constant. Note that from Equations (8), firm 1's FOCs are expressed as functions $z_{2}^{L}\left(z_{1}^{L}\right)$, which is increasing, whereas from Equations (9) firm 2's FOCs are decreasing functions. The point of intersection is the equilibrium taste levels $z_{1}^{L *}$ and $z_{2}^{L *}$, from which equilibrium prices are calculated. In the lemma below, we set conditions under which equilibrium occurs in certain regions.

Lemma 2. Assuming $\underline{z}+I_{L} \geq \Delta$, let $\left(2 \pi_{L}+\pi_{H}\right) \underline{z}+$ $\pi_{L} I_{L}<\bar{z}<\left(2 \pi_{L}+2\right) \underline{z}+\left(2 \pi_{L}+1\right) I_{L}+\pi_{H} \Delta$, there exist a unique equilibrium where exactly 2 firms will have positive market shares. The possible regions where the equilibrium lies include Regions 1, 2, 5 and 6. Moreover, the both low- and high-income markets are covered (i.e., the equilibrium does not lie in Region 3, 4 or 7).

The equilibrium region depends on the values of the exogenous parameters. The general results for determining equilibrium region are stated in the following proposition.

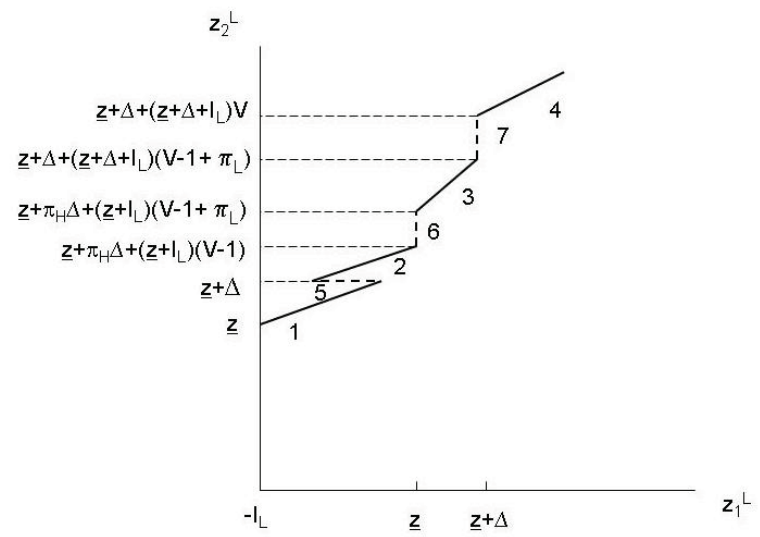

Figure 1: Firm 1's First Order Conditions
Proposition 3. When $\bar{z} \in\left[\left(2 \pi_{L}+\pi_{H}\right) \underline{z}+\right.$ $\left.\pi_{L} I_{L},\left(2 \pi_{L}+\pi_{H}\right) \underline{z}+\pi_{L} I_{L}+3 \pi_{L} \Delta\right]$, the equilibrium lies in Region 1. When $\bar{z} \in\left[\left(2 \pi_{L}+\pi_{H}\right) \underline{z}+\pi_{L} I_{L}+\right.$ $\left.3 \pi_{L} \Delta, 2 \underline{z}+I_{L}+\left(3 \pi_{L}+\pi_{H}\right) \Delta\right]$, the equilibrium lies in Region 5. When $\bar{z} \geq 2 \underline{z}+I_{L}+\left(3 \pi_{L}+\pi_{H}\right) \Delta$, if $V \geq \frac{\bar{z}+\underline{z}+2 I_{L}-\pi_{H} \Delta}{3\left(z+I_{L}\right)}$, then the equilibrium lies in Region 2, otherwise it lies in Region 6.

We derive the equilibrium indifference taste levels, prices, and revenues in these different regions. This characterizes the market structure and profitability given the economic conditions, in particular the consumer income distribution within a period.

Table 1: Equilibrium Prices in Regions 1, 2, 5, and 6

\begin{tabular}{ll}
\hline \hline & Prices \\
\hline & $p_{1}^{*}=\frac{\bar{z}-2 \underline{z}-I_{L}+(\bar{z}-\underline{z}) \frac{\pi_{H}}{\pi_{L}}}{3 C(V-1)}$ \\
Region 1 & $p_{2}^{*}=\frac{1}{3 C}\left[2 \bar{z}-\underline{z}+I_{L}+2(\bar{z}-\underline{z}) \frac{\pi_{H}}{\pi_{L}}\right]$ \\
\hline & $p_{1}^{*}=\frac{1}{C(V-1)}\left[\left(1+\frac{\pi_{H}}{\pi_{L}}\right)(\bar{z}-\underline{z})-\underline{z}\right.$ \\
& $\left.-I_{L}-2 \Delta\right]$ \\
Region 5 & $p_{2}^{*}=\frac{(\bar{z}-\underline{z})\left(1+\frac{\pi_{H}}{\pi_{L}}\right)-\Delta}{C}$ \\
\hline \multirow{2}{*}{ Region 2 } & $p_{1}^{*}=\frac{\bar{z}-2 \underline{z}-\pi_{H} \Delta-I_{L}}{3(C-1)}$ \\
\hline & $p_{1}^{*}=\frac{\underline{z}+I_{L}}{C}$ \\
Region 6 & $p_{2}^{*}=\frac{\bar{z}+\pi_{H} \Delta+I_{L}+\left(\underline{z}+I_{L}\right)(V-1)}{2 C}$ \\
\hline \hline
\end{tabular}

Table 2: Equilibrium Profits in Regions 1, 2, 5, and 6

\begin{tabular}{ll}
\hline \hline & Profits \\
\hline & $R_{1}^{*}=\frac{\pi_{L}}{9 C(V-1)}\left[\bar{z}-2 \underline{z}-I_{L}+(\bar{z}-\underline{z}) \frac{\pi_{H}}{\pi_{L}}\right]^{2}$ \\
Region 1 & $R_{2}^{*}=\frac{\pi_{L}}{9 C}\left[2 \bar{z}-\underline{z}+I_{L}+2(\bar{z}-\underline{z}) \frac{\pi_{H}}{\pi_{L}}\right]^{2}$ \\
\hline & $R_{1}^{*}=\frac{\pi_{L} \Delta}{C(V-1)}\left[\left(1+\frac{\pi_{H}}{\pi_{L}}\right)(\bar{z}-\underline{z})-\underline{z}\right.$ \\
& $\left.-I_{L}-2 \Delta\right]$ \\
Region 5 & $R_{2}^{*}=\frac{1}{C \pi_{L}}\left[\left(1+\frac{\pi_{H}}{\pi_{L}}\right)(\bar{z}-\underline{z})-\Delta\right]^{2}$ \\
\hline & $R_{1}^{*}=\frac{\left(\bar{z}-2 \underline{z}-\pi_{H} \Delta-I_{L}\right)^{2}}{9(C-1)}$ \\
Region 2 & $R_{2}^{*}=\frac{\left(2 \bar{z}-\underline{z}+\pi_{H} \Delta+I_{L}\right)^{2}}{9 C}$ \\
\hline & $R_{1}^{*}=\frac{\underline{z}+I_{L}}{C}\left[\bar{z}-\pi_{H} \Delta-I_{L}-2 \underline{z}\right.$ \\
& $\left.-\left(\underline{z}+I_{L}\right)(V-1)\right]$ \\
Region 6 & $R_{2}^{*}=\frac{\left[\bar{z}+\pi_{H} \Delta+I_{L}+\left(\underline{z}+I_{L}\right)(V-1)\right]^{2}}{4 C}$ \\
\hline \hline
\end{tabular}




\section{Innovating Firms}

This section describes the innovation race and firms' innovation decisions. Our setup follows the framework developed by Segal and Whinston (2007) with the extension of heterogeneity of innovation costs across firms [18].

There exist $\mathrm{M}$ firms who are potential entrants. Every period, they pick up a draw $\epsilon$ from a distribution $F(\cdot)$. This draw affects the cost of innovation, which is $\epsilon c\left(\phi_{i}(\epsilon)\right)$ and known to firms as the draws are realized. $\phi_{i}(\epsilon) \in(0,1)$ is the innovation rate of firm $i$ with the draw $\epsilon . c(\cdot)$ is a concave function.

Potential entrants make decisions in three stages: 1) Entry to innovation race - firms choose whether to innovate; 2) Innovation effort - firms choose the level of $R \& D$, which affects its probability to successfully innovate, hence the chance of market entry; 3) In case of market entry, firms choose their prices, which is described in the equilibrium results in the previous section.

Multiple innovators may succeed in developing new products. However, only one of these innovations is granted a patent. The firm with a patent then enters the product market and becomes an incumbent with the highest quality product. We use the simultaneous entry and exit setup, thus the lowest-quality incumbent is displace upon a new entry. The innovation model connects to the market structure analysis at this point, as the profits of a new entrant is characterized by the equilibrium results derived in Section 3.2.

If a firm chooses to innovate, it incurs a sunk innovation cost $f$. Let $\pi_{M}\left(\phi_{-}^{I}\right)$ denote the probability of a firm successfully creating a new product. $\phi_{-}^{I} \in[0,1]^{M}$ describes the innovation efforts of all the potential entrants. However, each period only one of these firms is granted a patent and enters the market, the probability of actually obtaining the patent is then denoted by $\lambda_{M^{l}}\left(\phi, \phi_{-}\right)$. $\phi_{-} \in[0,1]^{M-1}$ denotes the innovation efforts of the rest of potential entrants ${ }^{1}$. The value functions of the firms at different stages are listed below:

$$
\begin{aligned}
V^{0}\left(\epsilon, \phi_{-}\right)= & \max \left\{0,-f+\beta V^{E}\left(\epsilon, \phi_{-}\right)\right\} \\
V^{E}\left(\epsilon, \phi_{-}\right)= & \max _{\phi}\left\{\lambda_{M^{l}}\left(\phi, \phi_{-}\right) V_{J}^{I}\right. \\
& +\left(1-\lambda_{M^{l}}\left(\phi, \phi_{-}\right)\right) \beta E V^{0}\left(\epsilon^{\prime}, \phi_{-}^{\prime}\right) \\
& -\epsilon c(\phi)\}
\end{aligned}
$$

$$
\begin{aligned}
V_{i}^{I}\left(\epsilon, \phi_{-}\right)= & \pi_{M^{l}}\left(\phi_{-}^{I}\right)\left[R_{i-1}+\beta V_{i-1}^{I}\left(\epsilon, \phi_{-}\right)\right] \\
& +\left(1-\pi_{M^{l}}\left(\phi_{-}^{I}\right)\right)\left[R_{i}\right. \\
& \left.+\beta V_{i}^{I}\left(\epsilon, \phi_{-}\right)\right] \\
& i=2, \ldots, J \\
V_{1}^{I}\left(\epsilon, \phi_{-}\right)= & \pi_{M^{l}}\left(\phi_{-}\right) \beta E V^{0}\left(\epsilon^{\prime}, \phi_{-}^{\prime}\right) \\
& +\left(1-\pi_{M^{l}}\left(\phi_{-}\right)\right)\left[R_{1}\right. \\
& \left.+\beta V_{1}^{I}\left(\epsilon, \phi_{-}\right)\right]
\end{aligned}
$$

$V^{0}\left(\epsilon, \phi_{-}\right)$is the value function of firms at the start of the game; $V^{E}\left(\epsilon, \phi_{-}\right)$is the value function at Stage $1 ; V_{i}^{I}\left(\epsilon, \phi_{-}\right)$and $V_{1}^{I}\left(\epsilon, \phi_{-}\right)$are the value functions for incumbents producing product quality $i$ and the lowest quality product before exiting, respectively. It is easy to show that the dynamic programming problem described by equations (10)-(13) satisfies the Blackwell sufficient conditions, thus it has a unique fixed point in a bounded space.

Assuming $\epsilon \in\left\{\epsilon_{l}, \epsilon_{h}\right\}$ follows Bernoulli distribution, the probability of drawing $\epsilon_{h}$ is $\eta$. For simplicity, let the number of firms facing low innovation shocks in each period be $M^{l}$ (by the Law of Large Numbers $\left.M^{l} \approx(1-\eta) M\right)$. Following the formulation for multiple entrants case in Segal and Whinston's work [18], if both types of firms innovate, the probability of at least one firm successfully creating a innovation is,

$$
\pi_{M^{l}}\left(\phi_{-}^{I}\right)=\left[1-\left(1-\phi\left(\epsilon_{h}\right)\right)^{M-M^{l}}\left(1-\phi\left(\epsilon_{l}\right)^{M_{l}}\right]\right.
$$

If only low-cost firms innovate,

$$
\pi_{M^{l}}\left(\phi_{-}^{I}\right)=\left[1-\left(1-\phi\left(\epsilon_{l}\right)\right)^{M^{l}}\right]
$$

And in the former case, for any one firm, conditional on successful innovation, the probabilities of obtaining a patent for the high- and low-cost firms are

$$
\begin{aligned}
r\left(\phi_{-}^{h}\right)= & \sum_{x=0}^{M-M^{l}-1} \sum_{y=0}^{M^{l}}\left[\left(\begin{array}{c}
M-M^{l}-1 \\
x
\end{array}\right)\left(\begin{array}{c}
M^{l} \\
y
\end{array}\right)\right. \\
& \left.\frac{\left(\phi_{h}\right)^{x}\left(1-\phi_{h}\right)^{M-M^{l}-1-x}\left(\phi_{l}\right)^{y}\left(1-\phi_{l}\right)^{M^{l}-y}}{x+y+1}\right] \\
r\left(\phi_{-}^{l}\right)= & \sum_{x=0}^{M-M^{l}} \sum_{y=0}^{M^{l}-1}\left[\left(\begin{array}{c}
M-M^{l} \\
x
\end{array}\right)\left(\begin{array}{c}
M^{l}-1 \\
y
\end{array}\right)\right. \\
& \left.\frac{\left(\phi_{h}\right)^{x}\left(1-\phi_{h}\right)^{M-M^{l}-1-x}\left(\phi_{l}\right)^{y}\left(1-\phi_{l}\right)^{M^{l}-y}}{x+y+1}\right]
\end{aligned}
$$

The probability of obtaining a patent for this firm with high or low cost is, respectively, then,

$$
\begin{aligned}
\lambda_{M^{l}}\left(\phi\left(\epsilon_{h}\right), \phi_{-}^{h}\right) & =\phi\left(\epsilon_{h}\right) r\left(\phi_{-}^{h}\right) \\
\lambda_{M^{l}}\left(\phi\left(\epsilon_{l}\right), \phi_{-}^{l}\right) & =\phi\left(\epsilon_{l}\right) r\left(\phi_{-}^{l}\right)
\end{aligned}
$$

\footnotetext{
${ }^{1} \phi_{-}^{h}$ and $\phi_{-}^{l}$ are other firms' innovation efforts for a firm with high or low innovation costs respectively.
} 
In the latter case, the conditional probability for a given firm is

$$
r\left(\phi_{-}^{l}\right)=\sum_{k=0}^{k=M^{l}-1}\left[\frac{1}{k+1}\left(\begin{array}{c}
M^{l}-1 \\
k
\end{array}\right) \phi_{l}^{k}\left(1-\phi_{l}\right)^{M^{l}-1-k}\right]
$$

The equilibrium is the fixed point of the following correspondence:

$$
\phi(\epsilon)=\operatorname{argmax}_{\phi^{\prime} \in[0,1]}\left\{0,-f+V^{E}\left(\epsilon, \phi^{\prime}\right)\right\}
$$

In the following section, we discuss the numerical solutions to the firm's dynamic problem and derive insight on the impacts of different innovation policies and aggregate economic conditions on innovation.

\section{Equilibrium and Comparative Statics}

In this section, we will discuss the parameterizations and the comparative statics results based on the numerical analysis. First we show the change in equilibrium innovation rate with respect to different types of income shocks. And then the implications of public policies are discussed according to the results from varying sunk and variable innovation costs.

\subsection{Parameterization}

The aim of our analysis is to provide insight into the qualitative properties of equilibrium innovation rate under the effect of income shocks and different types of innovation policies. Although some parameters are chosen from standard values and previous literature, they are not based on data from some specific industries.

The discount rate $\beta=0.95$ implies the annual interest rate is approximately 5\%. $a$ in the utility function is 1.2 . The income per capital $\bar{I}$ is 0.9 . The relative high income $q_{h}$ is 1.11 . We assume half of consumers have high income. The upper bound of taste shock $\bar{z}$ is 4.2 , while the lower bound of the taste shock $\underline{z}$ is 1.2 . The sunk cost of innovation $f$ is set to 5 . As for the functional form of innovation cost $c(\cdot)$, we follow Aghion, et al.'s model and use quadratic form, $c(\epsilon)=\epsilon \phi^{2}[1]$. Firms with high variable innovation costs have $\epsilon_{h}=20$. Firms with low variable innovation costs have $\epsilon_{l}=12$. We also assume the number of potential entrants is 10 each period and the number of firms with high innovation costs is 5 . We set these numbers relatively small to reduce the computation load.

With the above parameterizations, both types of firms conduct innovation. The innovation rate for the firms with high innovation costs is 0.4641 . The innovation effort of the rest of firms is higher, 0.5964, as their innovation costs are lower. The equilibrium prices fall in Region 2 in Section 4.2. If we raise the lower bound of taste shock $\underline{z}$ to 2.2 and set $a=1.4$, then the equilibrium falls into Region 1. The firms with high innovation cost do not innovate. The firms with low innovation cost now invest higher and have innovation rate 0.7729 . We discuss firms' innovation behaviors in different regions in the following.

\subsection{Innovation and Income Shock}

We study two types of income shocks in this part of the numerical analysis, income inequality and income per capita. For income inequality, we hold the per-capita income $\bar{I}$ fixed and vary the income gap. For income per capita, we hold the income inequality fixed. These two experiments allow us to isolate the effect of each of the two factors.

With respect to income inequality, holding the income per capita $\bar{I}$ and proportion of low- and high-income segments, $\pi_{h}, \pi_{l}$ fixed, we vary the relative high income level $q_{h}$ to reflect the varying inequality. The results contrast sharply between Region 1 and Region 2 (recalling that the region where equilibrium falls is found endogenously by the parameter values that characterize the consumer preference and income, and thus the prices set by firms). In other words, varying income inequality within the range of the region conditions allows us to examine innovation in industries with certain consumer preferences and yielded notably distinct results.
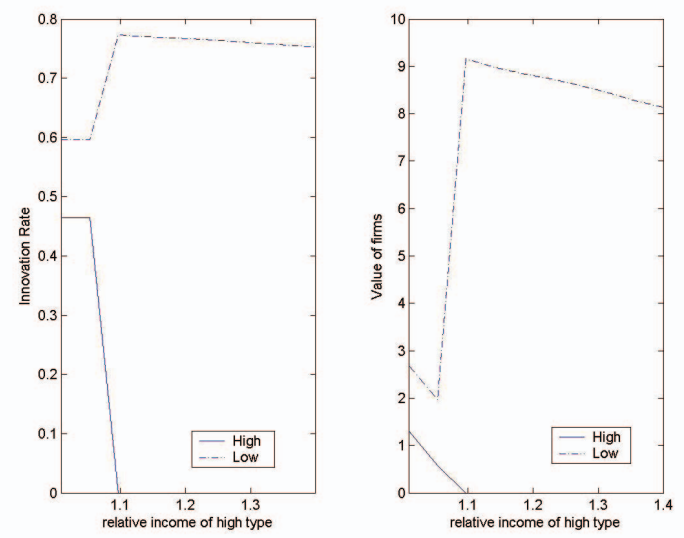

Figure 2: Innovation \& Income Inequality Region 1

In Region 1 (see Figure 2), where low-income is segmented between two products and high-income is solely captured by the higher quality firm, increas- 
ing inequality has an adverse effect on both innovate rate and firm values. The values of both types of firm decline with inequality due to reduced revenue. This may appear counterintuitive, as one would expect steeper inequality to benefit the higher-quality firm, which obtains the entire high-income segment as well as part of the low-income segment. Our finding offers the opposite explanation that with a wider income gap higher-quality firm actually lowers its price in equilibrium in order to reach the low-income level while still gaining the entirety of high-income segment. The aggregate innovation rate shows insignificant change until the high-variable-cost firms drop out of the innovation race, at which point the innovation rate declines significantly.
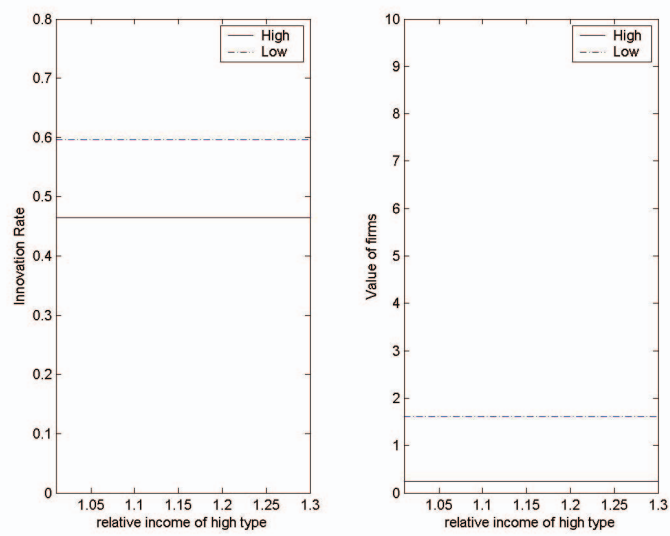

Figure 3: Innovation \& Income Inequality Region 2

Region 2's equilibrium results are independent of income inequality shifts when the income per capita is held fixed, due to the condition that both lowand high-income segments are shared between two firms. As a result, both firm values and innovation rates are constant in income quality (see Figure 3). This result is confirmed by the equilibrium profits in Table 2 where these profits are only related to $\bar{I}$ rather than $q_{h}$.

We further analyze the impact of per-capita income on innovation while holding fixed the income inequality parameter $q_{h}$. The results for the two regions look similar. Increasing per-capita income directly shifts the equilibrium revenues. The value of the firms that have a low variable cost increases first, where the high-variable-cost firms choose to not innovate; as the income level rises further, the value of the low-variable-cost firms drops and then increases in parallel with the high-variable cost firms (see Figures 4 \& 5).
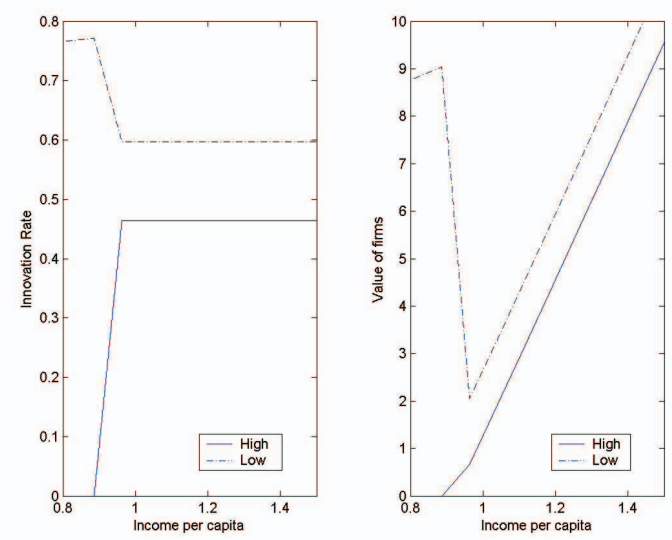

\section{Figure 4: Innovation \& Income per Capita -} Region 1

Thus, the improvement in overall income levels has three effects: 1) It encourages high-variable-cost firms to enter the $R \& D$ race; and 2) It intensifies competition and in turn shifts down low-variablecost firms' innovation rate; 3) It induces higher innovation rate among the existing innovators. This is linked to the increased demand and equilibrium profits in the product market where the successful innovator enters. Even though increased competition shifts down the equilibrium innovation rate of the low-variable-cost firms upon the entry of the high-variable-cost firms, the aggregate innovation is increased.
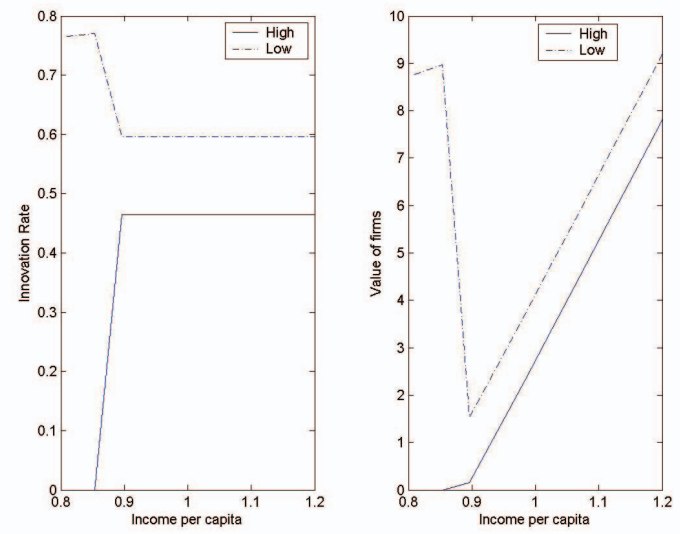

Figure 5: Innovation \& Income per Capita Region 2

Examination of different types of potential entrants reveals the underlying value gaps of the heterogeneous firms within the aggregate innovation rate. The procyclicality of $R \& D$ is reaffirmed in the aggregate sense. On the other hand, the argument that recession can also stimulate innovation is reflected in the first effect described above. The high-variable-cost firms drop out of the R\&D com- 
petition, thus reduced competition gives a boost to those remaining in the $\mathrm{R} \& \mathrm{D}$ race.

\subsection{Innovation and Policy}

We also look at the effects of varying the variable costs and sunk costs of the innovating firms. We vary the variable costs proportionally, since the heterogeneity resides in firms' variable costs.

As Figure 6 shows, as the variable cost decreases (examining the $\mathrm{x}$ axis from right to left) both the value and innovation rate increase for the low-variable-cost firms, while the high-variable-cost firms do not innovate. Similar to the previous observations with income per capita, further decreasing the variable cost results in a drop of the value and innovation rate of the low-variable-cost firms, as the high-variable-cost firms join the $\mathrm{R} \& \mathrm{D}$ race.

This result has an important R\&D tax policy implication. R\&D tax incentives can be designed to lower firms' $R \& D$ variable costs by providing more tax cuts for more dollars spent on technology innovation. In effect, these policies increase firms' profits for more R\&D activities. The similar three effects as those observed with the income per capita are drawn here. And we see that reducing variable $\mathrm{R} \& \mathrm{D}$ costs improves the aggregate innovation.

We also analyzed innovation rate against the innovation sunk cost, which refers to the fixed cost to set up an R\&D facility and purchase R\&D equipments, which may be applicable to start-up firms or those of small capacity. It seems counterintuitive that increasing fixed cost can encourage innovation rate. This finding is consistent for the low-variablecost firms, whereas for the high-variable-cost firms the innovation rate drops to zero when the fixed cost exceeds a certain threshold (see Figure 7).
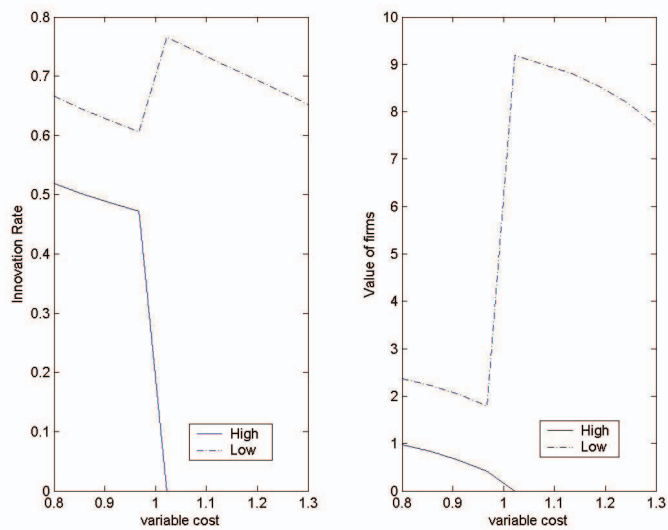

Figure 6: Innovation \& Variable Costs
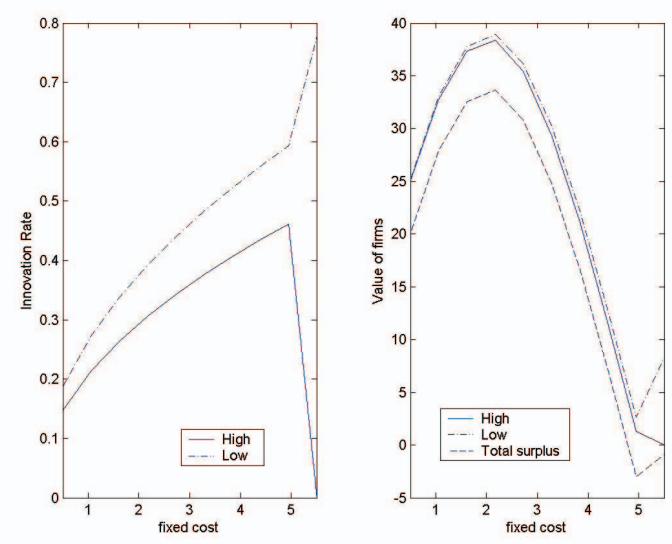

Figure 7: Innovation \& Fixed Costs

The partially positive effect of fixed cost is due to that the firms innovate more intensely in order to achieve a higher probability of success to offset the cost. However, above a certain threshold, the level of fixed cost no longer justifies innovation decision for those with high variable costs, in which case the high-variable-cost firms drop out of the $R \& D$ race, while the low-variable-cost firms' innovation rate has an upward jump caused by the dampened competition and continues to rise at a low rate.

In the aggregate sense, the optimal innovation is achieved in the first range when both types of firms innovate (see Figure 7). The insight here is that subsidies for innovation may not stimulate R\&D efforts, because the innovating firms the incentives to compete in an attempt to recover the sunk cost are diminished. In effect, firms become "lazier" as the profitability linked with innovation effort is more easily achieved. Furthermore, when an industry has a very high $R \& D$ sunk cost, only specialized or established firms that can efficiently carry out R\&D will compete in innovation.

\section{Concluding Remarks}

In this paper we have studied the change in innovation rate given income shocks to understand the innovation decision of firms under the impact of business cycles. We further analyzed the innovation rate while varying heterogeneous innovating firms' sunk and variable $R \& D$ costs and derived implications for innovation policies.

We found that effects of income shocks differ by varying either income inequality and per-capita income while holding the other fixed. Under income inequality change, the change in innovation rate has radically different results conditional on the equilibrium region. In Region 1, the innovation rate 
decreases as income levels become more polarized, because equilibrium revenues and prices are lowered to capture the poorer low-income consumers. In Region 2 , varying inequality has little effect since both low- and high-income markets are segmented.

Increasing per-capita income has similar results in the two regions, because firms' equilibrium profits increase in both Region 1 and Region 2. Raising the overall income levels has several effects. First, it encourages high-variable-cost firm to enter the R\&D race, because the profitability of the market is increased. However, introducing more innovating firms intensifies competition and reduces the other firms' equilibrium innovation rate. Thus there is a downward shift of the low-variable-cost firms' innovation rate as more firms enter the race. Regardless, the aggregate innovation rate increases with such a shock.

Our policy analysis showed consistent findings with the empirical evidence that subsidies tend to have ambiguous effects on innovation, whereas tax incentives have strongly positive impact. We provide the explanation that subsidies often directly compensate firms' sunk R\&D costs, thus reduce the premium that firms aim to recover through innovation success. While it moderates innovation efforts, dampened competition may have a positive effect on firms with lower variable costs. R\&D tax credits reduce firms' variable costs; therefore, they continuously stimulate innovation efforts while encouraging entry into the $R \& D$ race.

\section{References}

[1] Aghion, P., N, Bloom, R. Blundell, R. Griffith, and P. Howitt (2005), "Competition and Innovation: An Inverted-U Relationship", The Quarterly Journal of Economics, pp. 701-728.

[2] Aghion, P. and G. Saint-Paul (1998), "Virtues of Bad Times: Interaction between Productivity Growth and Economic Fluctuations," Macroeconomic Dynamics, 2(3), pp. 322-344.

[3] Barlevy, G. (2007), "On the Cyclicality of Research and Developmen", American Economic Review, 97(4), pp. 1131-1164.

[4] Bloom, N., R. Griffith, and J. Van Reenen (2002), "Do R\&D Tax Credit Work? Evidence from a Panel of Countries 1979-1997", Journal of Public Economics, 85, pp. 1-31.

[5] Caballero, R.J. and M.L. Hammour (1994), "The Cleansing Effect of Recessions," The American Economic Review, 84(5), pp. 13501368.
[6] Choi, Y.C., D. Hummels, C. Xiang (2009), "Explaining Import Quality: the Role of the Income Distribution", Journal of International Economics, forthcoming.

[7] Falk, M. (2004), "What Drives Business R\&D Intensity Across OECD Countries", WIFO Working Paper, No. 236/2004.

[8] Foellmi, R. and J. Zweimuller (2006), "Income Distribution and Demand-Induced Innovation", Review of Economic Studies, 73, pp. 941-960.

[9] Garcia-Quevado, G. (2004), "Do Public Subsidies Complement Business R\&D? A MetaAnalysis of Econometric Evidence", Kyklos, 57, pp. 87-102.

[10] Gorelick, D. (2009), "Obama to Seek Record Levels of Research Investment", America.gov, April 27, 2009.

[11] Hall, B.H. and J. Van Reenan (2000), "How Effective are Fiscal Incentives for R\&D? A Review of the Evidence", Research Policy, 29, pp. 449469.

[12] Lee, T. and L.L. Wilde (1980), "Market Structure and Innovation: A Reformulation", Quarterly Journal of Economics, 94(2), pp. 429-436.

[13] Loury, G. (1979), "Market Structure and Innovation", Quarterly Journal of Economics, 93(3), pp. 395-410.

[14] Mervis, J. (2009), "Amid the Gloom, Researchers Prepare for a Boom in Funding," Science, 323, March 6, 2009, pp. 1274-1275.

[15] Pilling, D. (2009), "From Boom to Gloom," The Financial Times, March 24, 2009.

[16] Rigby, D. K., K. Gruver, and J. Allen (2009), "Innovation in Turbulent Times", Harvard Business Review, June 2009, pp. 79-86.

[17] Schumpeter, J.A. (1918), The Crisis of the Tax State, in Economics and Sociology (Schumpeter 1991). p. 113.

[18] Segal, I. and M. Whinston (2007), "Antitrust in Innovative Industries", American Economic Review, 97(5), pp. 1703-1730.

[19] Shaked, A. and J. Sutton (1982). "Relaxing Price Competition Through Product Differentiation", Review of Economic Studies (49), pp. $3-13$.

[20] Terazono, E. (2009), "R\&D Decline will Hurt Competitiveness," The Financial Times, April 20, 2009.

[21] "The Obama-Biden Plan", Change.gov, http : //change.gov/agenda/economy_agenda/. 